\title{
Home Relocation and the Journey to Work
}

\author{
Early draft - Not for citation
}

\author{
Nebiyou Tilahun* $\quad$ David Levinson ${ }^{\dagger}$
}

\begin{abstract}
Relocation decisions are complex. Each household has a bundle of attributes that make a location attractive to it, including the ability to access different activity locations easily, neighborhood quality, house amenities etc. Relocating households have an opportunity to find housing closer to their work. Using data collected in the Twin Cities area, we investigate how commute time and distance change after a relocation.
\end{abstract}

\section{Introduction}

Relocation decisions are complex. Early models of urban structure framed the question of where people locate using a monocentric city model where location decisions are then framed as tradeoffs between transportation costs to jobs at the center and land costs (Alonso, 1964; Mills, 1972, Muth, 1969). Cities have always been much more complex than these models however, and recent changes include suburban jobs which have increased the job accessibility of far out suburbs. Residential preferences also look beyond access to jobs, to neighborhood quality, school quality, attributes of the home and so on; qualities which are not necessarily dependent on access to jobs. But in spite of these other considerations, studies have also shown stability in travel time expenditures (e.g. (Levinson and Kumar, 1994; Zahavi and Talvitie, 1980)) making the home-work connection an interesting area of study.

The stability of travel times over a long time period has led to the hypothesis that individuals have a set amount of time allocated to travel - a travel time budget (Zahavi and Talvitie, 1980). This hypothesize implicitly implies that rising congestion during peak demand hours would reduce the time allocated to travel to discretionary activities for those who experience it. Individuals then must change discretionary activity locations so as to reduce travel time to these other spheres, or

*Assistant Professor, Department of Urban Planning and Policy, University of Illinois at Chicago, 412 S. Peoria St. Suite 254, Chicago, IL 60607, USA, ntilahun@uic.edu

${ }^{\dagger}$ RP Braun-CTS Chair of Transportation Engineering; Director of Network, Economics, and Urban Systems Research Group; University of Minnesota, Department of Civil Engineering, 500 Pillsbury Drive SE, Minneapolis, MN 55455,dlevinson@umn.edu http://nexus.umn.edu 
find ways to reduce their commuting cost, or make a relocation decision. If there exists a travel time budget, then a relocation decision that seeks to reduce travel time to work in the face of rising congestion would allow for stability in the time allocated for travel for other activities. Otherwise, intolerance to exceeding the budget would lead either to a reduction in other travel or to a change of either the home or work location to stay within the budget.

However the existence of a travel time budget is disputed. In their review of the literature on Travel Time Budget, Mokhtarian and Chen (2004) call the idea of a travel time budget a theme that is persistent in the literature but elusive to pinpoint. What has led to the persistence is the observation that even as the employment landscape in major metropolitan areas is changing by suburbanizing jobs and housing. Alternative explanations for the stability has been given by others as arising from rational location decisions both by firms and individuals to keep travel time constant (Levinson and Kumar, 1994). Levinson (1998) has also posited that the increasing accessibility that arises from jobs that have followed suburbanizing homes has helped create this stability.

A position forwarded by Redmond and Mokhtarian (2001), has been that people do not necessarily try to reduce travel time but have preferences for particular commuting times. This view holds that commuting has positive utiltiy components that arise from traveling and activities that can be accomplished while traveling. Mokhtarian and Salomon (Mokhtarian and Salomon, 2001) also propose that individuals have an ideal travel time which varies by person and individuals adjust their travel so as to increase or decrease their travel time to meet this ideal. If true, relocation decisions would seek to maintain (not reduce) as travel time increases due to increasing congestion provided the initial conditions were ideal.

Studies have also looked at whether relocation decisions have changed the home-to-work commute. In their case study of the housing changes of an employer in Southern California, Wachs et al. (1993) for example find that trip lengths of the employees of the firm they studied did not increase substantially over a period of six years. Clark and Burt (1980) note a higher probability to relocate when the home-to-work distance is long. Looking at how commuting distances change, Clark et al. (2003) find that households that have high commutes to begin with shorten their commutes, and that women were more likely to shorten their commutes after a move than men. Levinson (1997), using metropolitan Washington data, investigates if recent movers have shorter commutes, and whether those that moved to new homes had longer commutes. His findings suggest that those who move, on average, maintain their commute durations.

Residential relocation decisions are much more deliberate than most other shorter term location decisions. These decisions can be motivated by a range of issues that have to do with changes in household structure, economic changes in the household, changes in the neighborhood etc. In addition to these factors, Clark and Withers (1999) do find that job changes can also serve as a trigger to housing relocation decisions. They find the effect of a job change is especially strong for single renters and weaker in two-worker households.

Selection of a new location upon relocation often has to balance competing needs of the household. Commute is one part of the consideration, but it is not the only one. Thus location decisions may not minimize commuting costs. For example Giuliano and Small Giuliano and Small (1993) 
find that the actual commute distribution is greater than what would be expected had people made commute-minimizing location choices. They conclude that commute is an important but likely one of several considerations in locations decision. But lowering (rather than minimizing) is always possible. Using longitudinal data Clark et al. Clark et al. (2003) ask whether households minimize commute distance when relocating and what differences exist between one worker and two worker households. They find evidence for reducing commute distance upon relocation with increased separation. They find that the trend is higher for women and lower for two-worker households when relocating residence.

The 2004 mobility report by the Census Bureau Schachter (2004) also helps place the importance of the commute in motivating relocation decisions. Most people in this data reported relocating due to housing related reasons $(51 \%)$ or family related reasons $(26 \%)$. Work related reason were reported as primary by $16 \%$ of respondents. A significant portion of these reported moving to a better home/apartment (20\%), moving to own a house (10\%), or a new job or transfer (9\%). The survey, which allowed for only one response per individual, did not consider secondary or tertiary roles played by commute distance/time in narrowing down a location among possible alternatives. As there are often many locations that can satisfy only one location consideration. In such cases, secondary reasons can play important roles to refine the location choice and the commute may have figured better in the decision matrix for relocators.

In the proceeding sections we will discuss the commuting changes experienced by individuals as a result of a relocation decision based on a survey conducted in the Twin Cities in 2007/2008. The next section discusses the survey and data, followed by analysis of the data and finally by summary of the research.

\section{Survey and Data}

A two phase online survey was administered to gather data on job finding, home finding and the social and technology networks that help people in the process . Postcards were sent to eight Zip code areas in the Twin Cities to 5000 people in each batch. Reminder postcards were sent a week following the original mailing in each case to solicit a response. The survey offered a \$5.00 gift card to participants who completed the survey as well as a drawing for a prize (an iPod).

On first mailing 192 and 205 cards were returned due to wrong addresses from each phase. Overall there were 268 and 297 respondents in phase 1 and 2 respectively (5.88\% of postcards that reached their destination). The areas were chosen to have economic and racial mix of respondents, as well as a city and suburban mix in the respondent pool. The distribution of demographic variables in the sample and that for the State of Minnesota is given in Table 1.

Each individual was asked about where they worked and lived, where they previously worked and lived as well as when they moved to their current home and when they started their work. In addition the respondents were also asked about their reason for moving, the type of housing they have chosen, and a host of other questions related to their demography and other travel activities. 
Table 1: Summary of Survey Subjects

\begin{tabular}{|l|l|l|l|}
\hline Variable & Group & Survey & Minnesota \\
\hline \multirow{2}{*}{ Sex } & Male & $39.8 \%$ & $49 \%$ \\
& Female & $60.2 \%$ & $51 \%$ \\
\hline Age (MN data for those between 18-65) & mean & 38.9 & 39.2 \\
\hline \multirow{2}{*}{ Household } & Renter & $22.5 \%$ & $25.4 \%$ \\
& Owner & $77.4 \%$ & $74.6 \%$ \\
\hline \multirow{5}{*}{ Education (MN data for those 25 and older) } & Less than high school & $0.4 \%$ & $9.3 \%$ \\
& High school & $16.6 \%$ & $50.6 \%$ \\
& Associates degree & $14.1 \%$ & $9.6 \%$ \\
& Bachelor's degree & $45.7 \%$ & $20.8 \%$ \\
& Grad/Professional degree & $23.1 \%$ & $9.6 \%$ \\
\hline \multirow{2}{*}{ Household Income } & Mean & $\$ 76,550$ & $\$ 81,644$ \\
& Median & $\$ 68,000$ & $\$ 66,809$ \\
\hline \multirow{3}{*}{ Race } & White & $90.3 \%$ & $89.4 \%$ \\
& Black & $3.4 \%$ & $3.5 \%$ \\
& American Indian & $0.2 \%$ & $1.1 \%$ \\
& Asian & $3.2 \%$ & $2.9 \%$ \\
& Other & $3.0 \%$ & $3.1 \%$ \\
\hline
\end{tabular}

\section{Analysis}

The analysis looks at how home-to-work commutes and whether travel times have changed for the subset of respondents who undertook relocation while they were at their current job. Both home and work locations were geo coded and travel times calculated based on google maps travel times using .This analysis is limited to people whose prior homes were within 120 minutes of driving travel time. Further it excluded those persons who were self employed and worked at home. A separate analysis of changes in commuting time is done for persons who changed jobs while at their current residence and whose current home is within 120 minutes of travel time to their previous employment location.

The sampled individuals fell into three areas of the metropolitan region: the city of Minneapolis, and cities in the the northwest and south eastern suburbs. Average commute times among respondents were shorter for those in Minneapolis regardless of whether people moved to the neighborhood and then found jobs or moved to their neighborhood while at their current workplace. Travel times in the two suburban areas however showed a difference based on the order of the latest event (residence or employment). In the southeast suburb, people who found homes while at their current job had a higher commute time than those who were in their current homes and found jobs. Those in the less job rich northwest suburbs had shorter travel time when residence was the latest decision. However, those who found their current jobs while at their current residence had on average higher commute times. These results are summarized in table 2. 
Further, relocating households while on the job achieved a reduction in previous travel times at least in the suburbs as compared to those changing jobs. As table 3 shows, average travel time savings when people located to the northwest suburbs was 7.6 minutes while those relocating to Minneapolis had no commute time savings (-0.81 minutes) and those in the southeast suburb saved 5.5 minutes over their previous commute.

In this sample at least the opportunities to reducing commute appear to be related to residential relocations rather than employment changes. Average changes in commute times are significantly different from zero for both suburbs when the person changed their residence, but average changes in commute as a result of workplace changes are zero.

Table 2: Mean commute travel times and $95 \%$ confidence intervals

\begin{tabular}{lllll}
\hline & All & All latest & \multicolumn{2}{c}{ Latest event } \\
\cline { 4 - 5 } Location & subjects & event known & Residence & Employment \\
\hline Southeast & $17.0 \mathrm{~N}=105$ & $17.3 \mathrm{~N}=84$ & $18.2 \mathrm{~N}=60$ & $15.4 \mathrm{~N}=25$ \\
suburb & $(14.9,19.1)$ & $(14.8,19.8)$ & $(14.8,21.5)$ & $(12.1,18.6)$ \\
\hline Minneapolis & $14.9 \mathrm{~N}=240$ & $15.1 \mathrm{~N}=168$ & $14.8 \mathrm{~N}=104$ & $15.8 \mathrm{~N}=64$ \\
& $(14.0,15.7)$ & $(14.0,16.3)$ & $(13.3,16.3)$ & $(14.0,17.5)$ \\
\hline Northwest & $17.1 \mathrm{~N}=83$ & $17.8 \mathrm{~N}=55$ & $16.1 \mathrm{~N}=33$ & $20.3 \mathrm{~N}=22$ \\
suburb & $(15.2,19.1)$ & $(15.4,20.1)$ & $(13.0,19.2)$ & $(16.6,24.0)$ \\
\hline
\end{tabular}

Table 3: Time savings by changing residence or jobs

\begin{tabular}{lll}
\hline & \multicolumn{2}{c}{ Latest event } \\
\cline { 2 - 3 } Location & Residence* $^{*}$ Employment \\
\hline SE suburb & $-5.50(-10.9,-0.01)$ & $-2.1(-6.1,1.9)$ \\
Minneapolis & $-0.81(-2.0,0.4)$ & $-0.16(-2.1,1.8)$ \\
NW suurb & $-7.59(-14.6,-0.5)$ & $-2.24(-10.8,6.3)$ \\
\hline${ }^{*}$ Current commute minus commute from previous home to current work \\
${ }^{+}$Current commute minus commute from current home to previous work
\end{tabular}

In the web based survey administered for this study, the primary, secondary and tertiary relocation reasons cited among all respondents are given in table 4. The primary reasons most often cited by the respondents are cost of the unit and affordability of the area followed by closeness to work and closeness to family and friends. Aggregated together home and neighborhood related reasons make up a majority of the reasons cited. "Being close to work" is cited frequently as one of the top three reasons for relocation with $36.7 \%$ of respondents whose previous home was in the metropolitan area of the Twin Cities selecting it. Figure 1 shows the previous-home-to-work and current hometo-work distances. It is clear that many maintain or reduce their commute distance upon relocation. The figure also shows that most of those that cited commute as a reason for relocating did reduce their home-to-work distance from what it would have been had they not relocated.

Relocation after finding employment can be an immediate or long term consideration. How soon relocation takes place can depend on the circumstances of the relocators' residence (rent/own, 


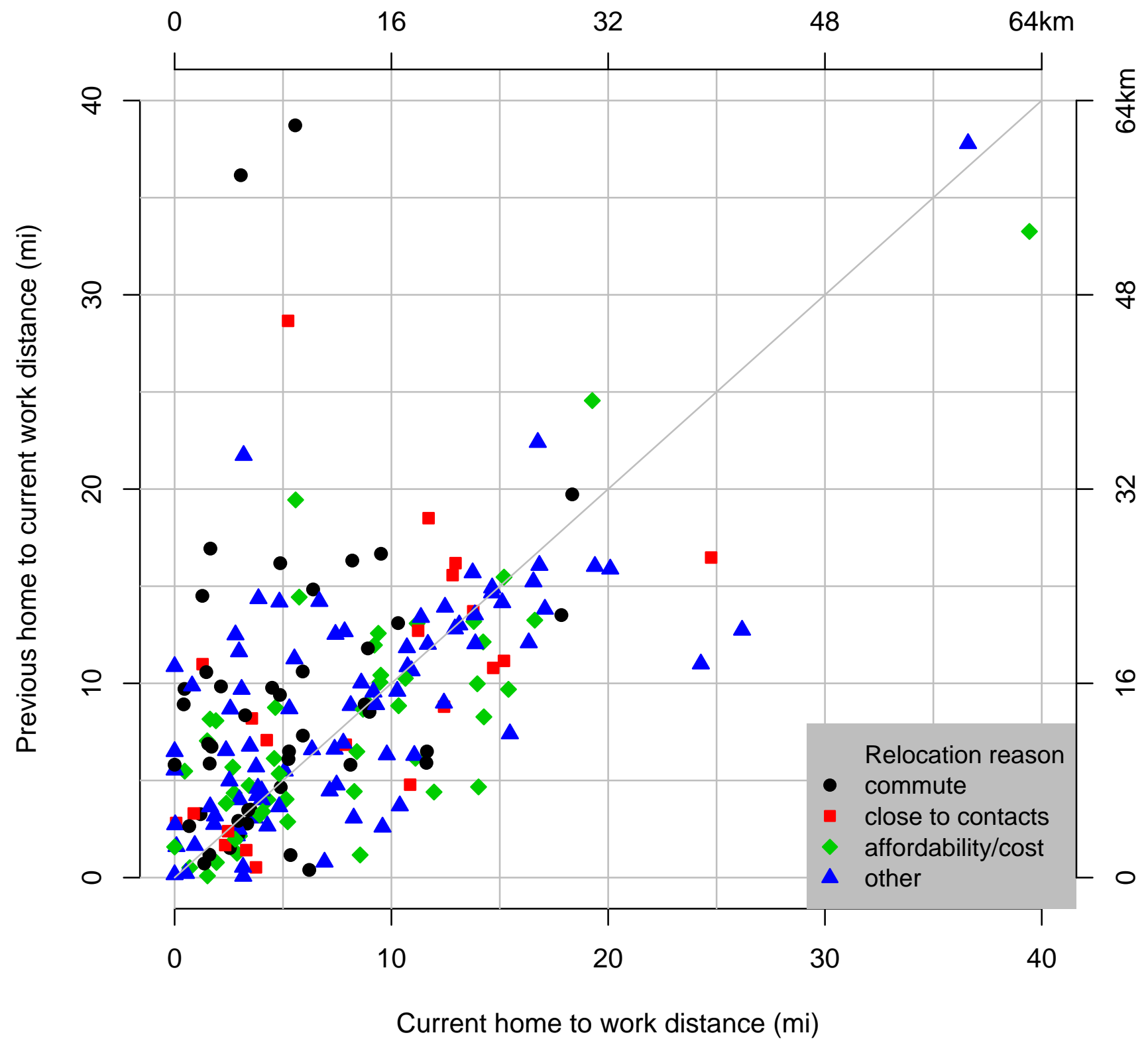

Figure 1: Distance between home and work before and after relocation for individuals who have relocated since finding their current work. 
Table 4: Top three reasons for relocation among those whose previous home was in the Twin Cities metropolitan area (percentages)

\begin{tabular}{l|rrr}
\hline & Reason 1 & Reason 2 & Reason 3 \\
\hline Cost of living/affordability & 27.89 & 21.09 & 13.83 \\
Close to work & 17.01 & 12.93 & 8.16 \\
Close to family/friends & 10.43 & 12.47 & 7.94 \\
Bike friendly area & 0.23 & 1.36 & 2.49 \\
Close to transit & 1.13 & 2.49 & 2.27 \\
Close to the city & 14.74 & 14.06 & 12.7 \\
Close to church & 0.91 & 2.04 & 1.13 \\
Close to open spaces & 2.95 & 6.58 & 8.62 \\
Larger lot size & 1.59 & 1.81 & 3.17 \\
Away from the city & 0.68 & 0.23 & 0.91 \\
Residence unit features & 7.94 & 5.44 & 6.35 \\
Safety & 1.81 & 3.17 & 3.63 \\
Kid friendly neighborhood & 1.36 & 3.4 & 5.67 \\
Good school district & 3.17 & 2.04 & 2.72 \\
Investment value of home & 2.27 & 3.4 & 6.35 \\
Other & 2.04 & 1.81 & 1.36 \\
Unreported & 3.85 & 5.67 & 12.7 \\
\hline Count & & 441 & \\
\hline
\end{tabular}

location etc.) and lifestyle and household characteristics at the time of employment as well as the characteristics of the new employment affect this decision. For instance a renter who found employment farther from their rental unit may find it easier to relocate to accommodate the new commute than a homeowner. Larger households, or dual earner households may find it more difficult to relocate. A person planning to buy a house next may find the costs of immediate relocation not worth any of the benefits relocation provides. Those who like their neighborhood, or have numerous local friends may opt to not relocate or relocate closer to their previous location while achieving the other goals of relocation. Age, income, household size and so on which influence the lifestyle of the decision makers can also have impacts on relocation considerations.

Among the competing considerations that relocating households have, this section hypothesizes that individuals with larger social contacts in their neighborhood are less likely to move, or when they move they are more likely to move shorter distances away from where they were as compared to those that have fewer contacts in close proximity. Alternately as well individuals that have a large circle of close contacts around the metropolitan area are expected to relocate more freely. 


\section{Commute Outcomes of Relocation After Finding Employment}

In this section, we uncover relationships between job finding, tenure before relocation, new commute and how far away people relocate from their previous location using variables reported from the survey discussed above. The influence of job finding methods, social contacts, household and personal variables and the interdependence between how long after job finding the person relocates, the new locations distance from the previous home, and the new commute are explicitly considered. The relationship between these variables can be studied using path analysis.

Path analysis has its origins in biology in the work of Sewall Wright Wright (1920, 1921, 1923 , 1934). Wright first used the method in linking the degree to which heredity and environment affect the color of guinea-pigs' offsprings Wright (1920). The method has often been called causal modeling, however, as Denis and Legerski Denis and Legerski (2006) point out the case for causality has to lie outside of the statistical modeling technique.

Wright Wright (1985) describes path analysis as:

"...a way of dealing with interrelated variables. It is based on the construction of qualitative diagram in which every included variable, measured or hypothetical, is represented (by arrows) either as completely determined by certain others (which may be represented as similarly determined) or as an ultimate factor."

The method is one where a hypothesized set of relationships that are dependent on one another can be tested. Path models employ both standardized and absolute (measured) variables in estimation. For the standardized estimates, each of the variables is adjusted so that its mean is zero and its standard deviation is equal to one. The standardized estimates of the path model give how many standard deviations the endogenous variable moves in response to a change in one standard deviation of the exogenous variable when all other variables are held constant. The regression coefficients, estimated from the observed variables, measure the contribution of each of the independent variables on the dependent variables.

Miller Miller (1977) summarizes the assumptions behind path models as follows:

- change in one variable is always a linear function in the change of another variable.

- there is no reciprocal causation.

- one must be able to prioritize the ordering of effects (tease out the primary effect from the indirect effect).

- the disturbances of the dependent variables are uncorrelated

- the usual assumptions in regression analysis are met (independence, homoscedasticity, etc.)

The hypothesized relationships between individual characteristics, job search, tenure at home, commuting distance, and different outcomes of the relocation decision is shown in figure 2 . This relationship is imposed a priori based on the assumptions described in the proceeding paragraphs. Weights for the paths were estimated using the CALIS procedure of SAS software Inc. (2004). 
Some paths were dropped during the analysis when found to be unimportant in explaining the hypothesized relationship. The final estimated model is shown in figure 3 .

The assumptions behind the relationships in the path model are as follows. Relocation decisions after finding new employment are hypothesized to take time after finding work. This time is expected to be influenced by the persons' living arrangement, how they found their job, their age, what kind of move they aim to make, as well as their commute to the new work location. Younger individuals, as well as renters are expected to relocate faster. Individuals who aim to rent next are also expected to move sooner than those who aim to purchase their next residence. In addition, the longer their commute to their new employment, the quicker individuals are expected to relocate.

Job finding methods are also expected to have an impact on tenure after finding new employment. If the job was found through a contact, relocation is expected to occur sooner because of the implied confidence in the security of the new job. Individuals who found their job through the use of internet and newspaper are also expected to relocate sooner relative to those using formal means because of the longer distance outcomes of these methods.

In choosing their new residential location, individuals with smaller households are expected to be able to lower their commute than those with larger households who have to balance competing commute and location requirements. Those with larger incomes are expected to be motivated by other considerations such as larger homes, lot sizes, and amenities whose selection may take them farther from their employment site.

Individuals whose commutes become longer when finding new employment are expected to lower or maintain their previous home-to-work distance upon relocation. In addition, those individuals who relocate sooner are expected to lower their commute than those that stay at their current location under the new commute. In this arrangement, the commute right after relocation is expected to impact the new home-to-work distance directly, and indirectly through their tenure at their previous location.

Another consideration in relocation is also how far away from their current neighborhood a household relocates. Naturally the longer they have lived in the neighborhood, the more they know about it relative to other areas and the more attached they could be to it. How far away relocation occurs in this case is expected to be negatively impacted by how long after finding work, the relocation takes place.

In addition, the number of contacts a person has in their neighborhood can negatively influence how far away they relocate if closeness to these contacts is important to them. Alternately if an individual has a large number of contacts spread across the metropolitan area, it could mean that they have opportunities to relocate at locations that are farther from their current neighborhood while maintaining closeness to a desirable number of their contacts. The number of contacts a person has and the percentage of contacts in a 3 mile radius after relocation are used as indicator variables to how many local and total contacts the respondents had at their previous location.

The path model shown here encapsulates decisions taken over a long period of time. Job finding 
is the earliest event, and relocation is the latest event. These are separated by the tenure at the previous location after finding the current job. The age at which the current job was found and the years spent at the previous home add up to make the age at relocation. The new home-to-work distance and the previous home-to-current-home distance are outcomes of the latest decision.

In light of these time differences it is essential to establish which variables are from the time of the decision and which are not. Household size, household income, and household vehicles are from the time of the survey, and should be taken as indicator variables of lifestyle at the time of the decision. Just over 54\% of the relocations considered here have occurred since January of 2004, and a further $20 \%$ since 2000 . The number of contacts $\left(C_{S}\right)$ and the percentage of contacts within three miles of home $\left(C_{p 3}\right)$ are variables reported as of the time of the survey, and these should be considered as indicator variables of how many total close contacts a person has and how many of those are in close proximity to them.

Many of the hypothesized relationships hold while a few are found having the opposite direction from what was hypothesized or to not be relevant.

Contrary to what was expected, older individuals relocated faster than younger individuals. For each additional year a person is older when taking a new job, tenure at their older home decreased by $1.98 \%$. Individuals that would relocate to a rental unit spend $27 \%$ less time at their residence than people who purchase their next location, and those that were renting their residence at the time of finding work relocate $36 \%$ sooner than homeowners. Owners are more committed to their residences, and the costs of relocation are much higher to them than to renters. Those who plan to own also take longer to relocate because the home search takes planning and time. Since home ownership involves risks that renters do not endure, getting into the "right" home can be a more deliberate process.

\begin{tabular}{rrrrrr}
\multicolumn{6}{c}{ Table 5: Goodness of Fit of Measures } \\
& Chi-squared & df & p & NFI & NNFI \\
\hline Null Model & 333.16 & 78 & 0.000 & - & - \\
Estimated Model & 15.10 & 19 & 0.716 & 0.955 & 1.063 \\
\hline
\end{tabular}

Those who found their job through the internet stayed the least amount of time at their residence when finding a new job. Since the trend for internet users persists even after controlling for age and distance, there may be unseen variables among those that use the internet to find jobs that makes them footloose and less attached to their residential location. Those who used contacts have the anticipated direction, but the magnitude is less than that for internet users, and statistically it is not significant. The estimate for newspaper users is as anticipated, but it too is not statistically significant.

These observed variables have direct and indirect impacts on the home-to-work distance after relocation $(D)$ and how far away from their current home individuals relocate $\left(D_{h h}\right)$. The home-towork distance after relocation depends weakly on how soon the relocation occurred, but is strongly related to what the commute distance before relocation was, and with household income. Each 


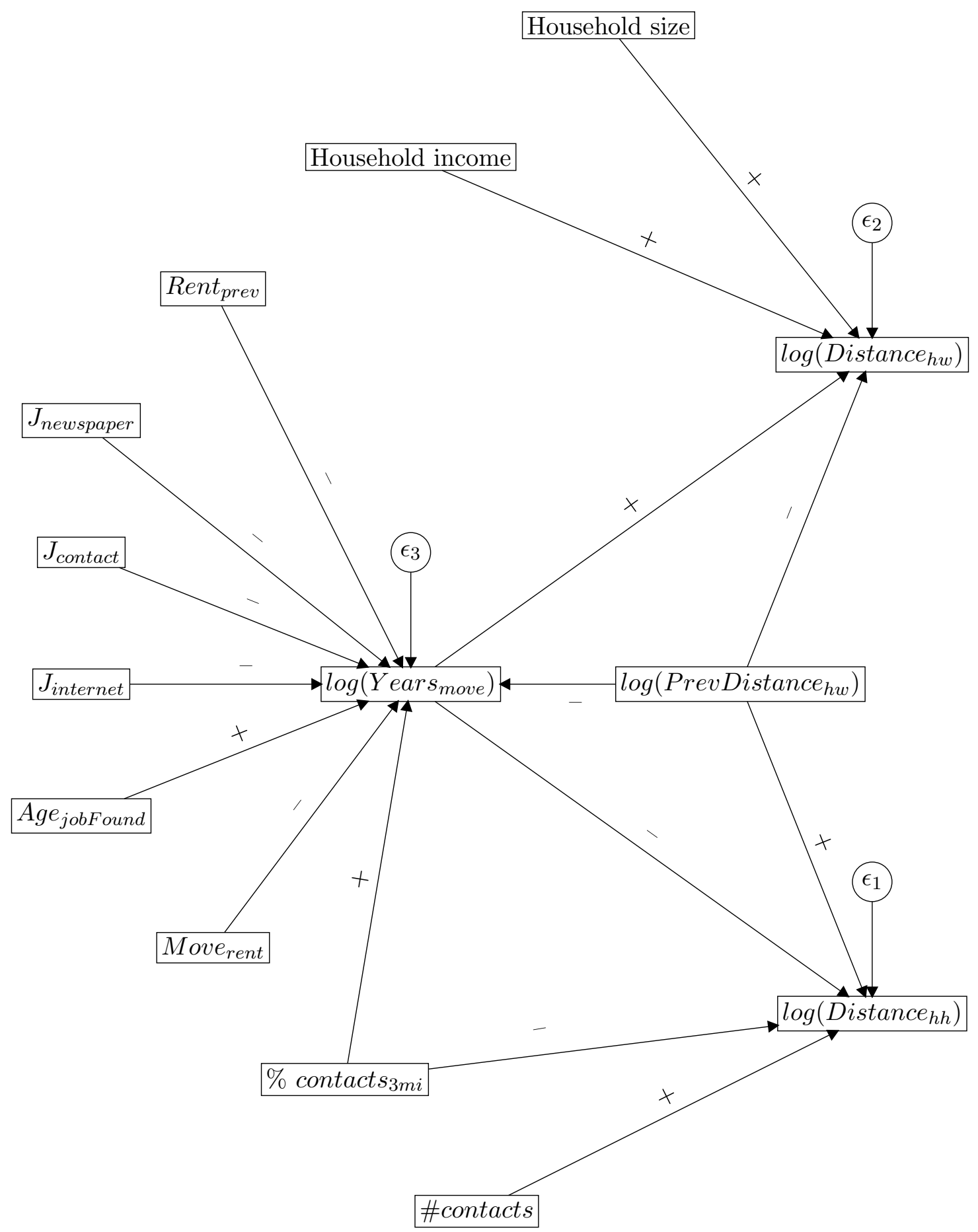

Figure 2: Proposed path model of tenure, commute, and moving distance after finding employment (correlations between exogenous variables not shown.) 


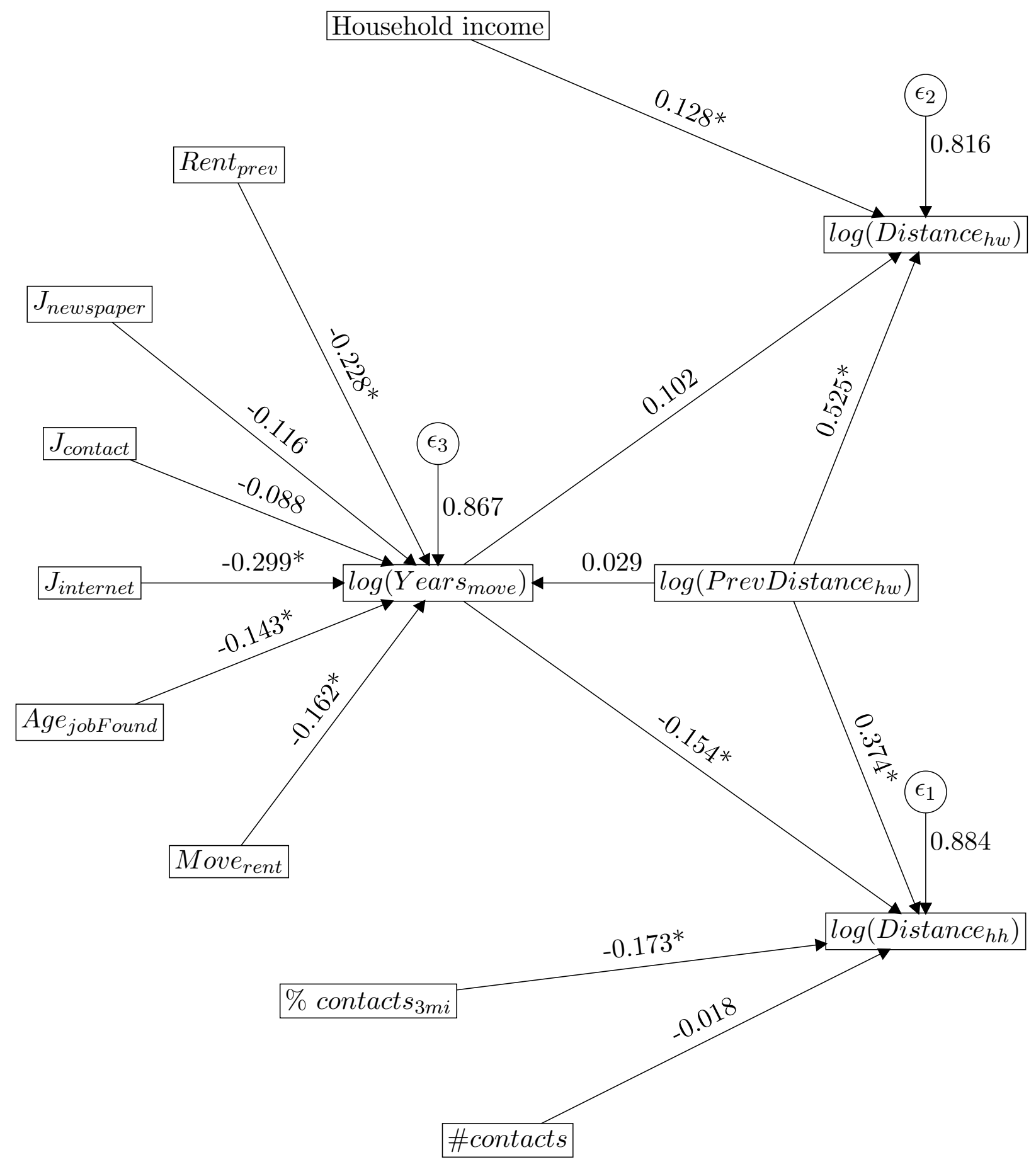

Figure 3: Estimated path model of tenure, commute, and moving distance after finding employment (correlations between dependent variables not shown. See Table 7). Estimates that are significant at the .05 level are marked with $\mathrm{a} *$. 
Table 6: Estimated path model for relocation after finding work

\begin{tabular}{|c|c|c|c|c|c|}
\hline & & Variable & Estimate & Std. Error & t-stat \\
\hline \multirow{10}{*}{$\begin{array}{l}\text { Time between } \\
\text { finding } \\
\text { work and } \\
\text { relocation } \\
\left(\log \left(Y_{m v}\right)\right)\end{array}$} & Distance before move & $\log \left(D_{p}\right)$ & 0.030 & 0.070 & 0.43 \\
\hline & Job through contact & $J_{c}$ & -0.155 & 0.135 & -1.14 \\
\hline & Job through internet & $J_{i}$ & -0.875 & 0.198 & $-4.41^{*}$ \\
\hline & Job through newspaper & $J_{n}$ & 0.278 & 0.180 & 1.55 \\
\hline & Age job taken & $A_{j}$ & -0.020 & 0.010 & $-2.06^{*}$ \\
\hline & Moving to rental? & $R_{c}$ & -0.317 & 0.149 & $-2.13 *$ \\
\hline & Rented before move? & $R_{p}$ & -0.444 & 0.142 & $-3.12 *$ \\
\hline & Error variance & & 0.555 & & \\
\hline & Total variance & & 0.740 & & \\
\hline & $R^{2}$ & & 0.249 & & \\
\hline \multirow{6}{*}{$\begin{array}{l}\text { Commute } \\
\text { distance } \\
\text { after move } \\
(\log (D))\end{array}$} & Years to move & $\log \left(Y_{m v}\right)$ & 0.103 & 0.064 & 1.59 \\
\hline & Distance before move & $\log \left(D_{p}\right)$ & 0.541 & 0.066 & $8.17 *$ \\
\hline & Household income (1000) & $I_{h}$ & 0.027 & 0.014 & $1.97 *$ \\
\hline & Error variance & & 0.499 & & \\
\hline & Total variance & & 0.750 & & \\
\hline & $R^{2}$ & & 0.335 & & \\
\hline \multirow{7}{*}{$\begin{array}{l}\text { Previous to } \\
\text { new home } \\
\text { distance } \\
\left(\log \left(D_{h h}\right)\right)\end{array}$} & Years to move & $\log \left(Y_{m v}\right)$ & -0.164 & 0.073 & $-2.24 *$ \\
\hline & Distance before move & $\log \left(D_{p}\right)$ & 0.406 & 0.076 & $5.32 *$ \\
\hline & Num. of contacts $(/ 10)$ & & -0.009 & 0.036 & -0.26 \\
\hline & $\%$ of contacts in $3 \mathrm{mi}$ & $C_{p 3}$ & -0.009 & 0.004 & $-2.46^{*}$ \\
\hline & Error variance & & 0.655 & & \\
\hline & Total variance & & 0.837 & & \\
\hline & $R^{2}$ & & 0.218 & & \\
\hline
\end{tabular}

Significance: $*$ p-value $\leq 0.05$

percentage increase in 'previous home-to-work distance' is positively related to the new homework-distance. It suggests that those who had tolerated longer commutes before, will tolerate them still after a move.

Though not statistically significant, the model also suggests that those who experienced the previous home-to-work distance for a longer period of time after finding their work also had longer commutes. This is consistent with the idea that those who do not relocate quickly relocate for reasons other than commute. A household's income also plays a role in the home-to-work relocation after a move. With each $\$ 1,000$ increase in household income, the new home-to-work distance increases by $2.7 \%$. This is consistent with our hypothesis that wealthier households might be concerned about other aspects that are not commute related. No direct relationship was found between household size and home-to-work distance.

In choosing the new neighborhood, another factor that is considered is how far away the person 
Table 7: Correlations among exogenous variables for relocation after finding work (only those above 0.1 reported)

\begin{tabular}{|l|l|r|}
\hline Variable 1 & Variable 2 & Correlation \\
\hline$A_{j}$ & $C$ & 0.159 \\
$A_{j}$ & $C_{p 3}$ & 0.126 \\
$A_{j}$ & $R_{p}$ & -0.215 \\
$R_{c}$ & $R_{p}$ & 0.258 \\
$I$ & $R_{c}$ & -0.285 \\
$I$ & $R_{p}$ & -0.253 \\
$J_{c}$ & $I$ & 0.107 \\
$J_{c}$ & $C_{p 3}$ & 0.138 \\
$J_{c}$ & $R_{p}$ & -0.122 \\
$J_{i}$ & $A_{j}$ & -0.178 \\
$J_{i}$ & $R_{c}$ & 0.277 \\
$J_{i}$ & $I$ & -0.141 \\
$J_{i}$ & $R_{p}$ & 0.173 \\
$\log \left(D_{p}\right)$ & $I$ & 0.184 \\
$\log \left(D_{p}\right)$ & $J_{i}$ & 0.109 \\
$\log \left(D_{p}\right)$ & $C$ & -0.112 \\
$\log \left(D_{p}\right)$ & $C_{p 3}$ & -0.192 \\
$C$ & $R_{c}$ & -0.169 \\
$C$ & $R_{p}$ & -0.131 \\
$C_{p 3}$ & $R_{c}$ & -0.141 \\
$C_{p 3}$ & $R_{p}$ & -0.169 \\
\hline
\end{tabular}

moves from their previous neighborhood. The $D_{h h}$ variable measures this distance. As hypothesized earlier, an important consideration for how far people moved from their previous location is assumed to be neighborhood quality as well as the contacts that they would leave behind. The model shows that those that didn't relocate as quickly did not relocate farther. For each additional year stayed at the home before relocation, the previous home to new home distance reduces by $1.6 \%$.

Another important variable that indicates how far a person moves is the percentage of contacts that live around them. Here the role of contacts is clear. The model suggests that for each percentage gain in the proportion of close contacts in a 3 mile radius, the relocation distance from their previous home is reduced by $0.9 \%$. The significance of the relationship supports the hypothesis that the people who have a larger proportion of their contacts close by try to stay close to those contacts when moving. 
Table 8: Overall and indirect effects of exogenous variables on relocation, commute and tenure

\begin{tabular}{|l|r|r|r|r|r|}
\hline & \multicolumn{3}{|c|}{ Overall effect } & \multicolumn{2}{c|}{ Indirect effect } \\
\hline & $\log (D)$ & $\log \left(D_{h h}\right)$ & $\log \left(Y_{m v}\right)$ & $\log (D)$ & $\log \left(D_{h h}\right)$ \\
\hline $\log \left(D_{p}\right)$ & 0.544 & 0.401 & 0.030 & 0.003 & -0.005 \\
$J_{c}$ & -0.016 & 0.025 & -0.155 & -0.016 & 0.025 \\
$J_{i}$ & -0.081 & 0.13 & -0.792 & -0.081 & 0.130 \\
$J_{n}$ & 0.029 & -0.046 & 0.278 & 0.029 & -0.046 \\
$A_{j}$ & -0.002 & 0.003 & -0.020 & -0.002 & 0.003 \\
$I$ & 0.027 & 0 & 0 & 0 & 0 \\
$C$ & 0 & -0.009 & 0 & 0 & 0 \\
$C_{p 3}$ & 0 & -0.009 & 0 & 0 & 0 \\
$R_{c}$ & -0.034 & 0.054 & -0.329 & -0.034 & 0.054 \\
$R_{p}$ & -0.046 & 0.073 & -0.448 & -0.046 & 0.073 \\
$\log \left(Y_{m v}\right)$ & 0.102 & -0.164 & 0 & 0 & 0 \\
\hline
\end{tabular}

\section{Summary}

This chapter looked at commuting outcomes of job finding, and the commuting outcomes of relocations. One of the hypothesis that was tested is that job search methods can impact the commute distance because of the ways in which information is gathered. Specifically it was hypothesized that jobs found through internet searches would be on average farther out than traditional methods. The findings from the first part of this chapter support this hypothesis. In addition it was also found that commute distances from newspaper found jobs were also longer than jobs found through formal means or contacts.

The relationship between job search, tenure, relocation, and social networks was also studied using path analysis. The findings suggest that relocation costs (renting before, and moving to a rental) were instrumental in how quickly individuals relocated after finding their work. Job searchers who used the internet to find their current employment also relocated faster reinforcing the hypothesis from the first section of the analysis.

Contact found jobs did not show particular patterns in regards to residential tenure. Other social network variables were found important in the relocation choice. For example, the percentage of contacts that are within a 3 mile radius of a person (self-reported) has a negative relationship with how far away one relocates. This suggests that social networks have an influence over residential location decisions. This role, though essential from the decision makers perspective, may limit the reductions in commute that may be achieved through relocation. 


\section{References}

Alonso, W. (1964). Location and Land Use: Toward a General Theory of Land Rent. Harvard University Press, Cambridge, Mass.

Clark, W. A. V. and Burt, J. (1980). The impact of workplace on residential relocation. Annals of the Association of American Geographers, pages 59-67.

Clark, W. A. V., Huang, Y., and Withers, S. (2003). Does commuting distance matter? commuting tolerance and residential change. Regional Science and Urban Economics.

Clark, W. A. V. and Withers, S. D. (1999). Changing jobs and changing houses: Mobility outcomes of employment transitions. Journal of Regional Science.

Denis, D. and Legerski, J. (2006). Causal modeling and the origins of path analysis. Theory \& Science.

Giuliano, G. and Small, K. (1993). Is the journey to work explained by urban structure? Urban Studies.

Inc., S. I. (2000-2004). Sas 9.1.3. Cary, NC.

Levinson, D. (1997). Job and housing tenure and the journey to work. The Annals of Regional Science.

Levinson, D. (1998). Accessibility and the journey to work. Journal of Transport Geography.

Levinson, D. and Kumar, A. (1994). The rational locator: Why travel times have remained stable. Journal of the American Planning Association.

Miller, M. (1977). Potentials and pitfalls of path analysis: A tutorial summary. Quality and Quantity.

Mills, E. S. (1972). Studies in the Structure of the Urban Economy. Johns Hopkins Press.

Mokhtarian, P. and Chen, C. (2004). TTB or not TTB, that is the question: a review and analysis of the empirical literature on travel. Transportation Research Part A.

Mokhtarian, P. and Salomon, I. (2001). How derived is the demand for travel? some conceptual and measurement considerations. Transportation Research Part A.

Muth, R. F. (1969). Cities and Housing; The Spatial Pattern of Urban Residential Land Use. The University of Chicago Press.

Redmond, L. and Mokhtarian, P. (2001). The positive utility of the commute: modeling ideal commute time and relative desired commute amount. Transportation.

Schachter, J. P. (March 2004). Geographical mobility: 2002 to 2003. Technical report, US Census Bureau, Washington, D.C. 
Wachs, M., Taylor, B. D., Levine, N., and Ong, P. (1993). The Changing Commute: A Case-study of the Jobs-Housing Relationship over Time. Urban Stud, 30(10):1711-1729.

Wright, S. (1920). The relative importance of heredity and environment in determining the piebald pattern of guinea-pigs. Proceedings of the National Academy of Sciences, 6:320-332.

Wright, S. (1921). Correlation and causation. Journal of Agricultural Research.

Wright, S. (1923). The theory of path coefficients a reply to niles's criticism. Genetics.

Wright, S. (1934). The method of path coefficients. The Annals of Mathematical Statistics, 5(3):161-215.

Wright, S. (1985). Path coefficientes and path regressions: Alternative or complementary concepts? In Blalock, H. M., editor, Causal Models in the Social Sciences, chapter 3, pages 39-53. Aldine Transaction. Reproduced from S. Wright, "Path Coefficientes and Path Regressions: Alternative or Complementary Concepts?" Biometrics 16 (1960).

Zahavi, Y. and Talvitie, A. (1980). Regularities in travel time and money expenditures. pubsindex.trb.org. 